\title{
18 Climate-Resilient \\ Agricultural Practices in the Saline-Prone Areas of Bangladesh
}

\author{
Muhammad Abdur Rahaman, Md. Sahadat \\ Hossain, and Md. Iqbal Hossain
}

\section{CONTENTS}

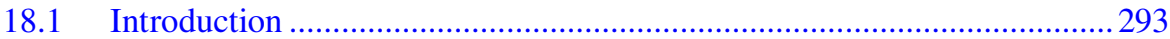

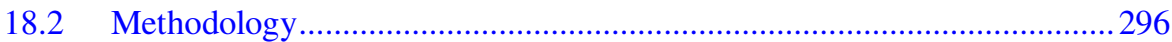

18.2.1 Household Survey ………………………………………........296

18.2.2 Focus Group Discussion............................................................296

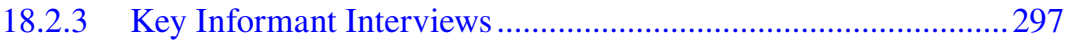

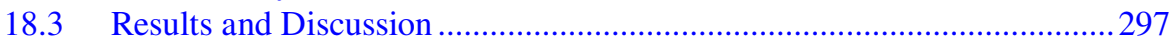

18.3.1 Household Types and Respondents ...........................................297

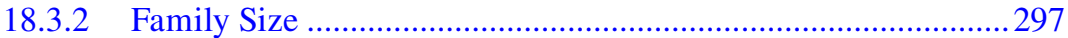

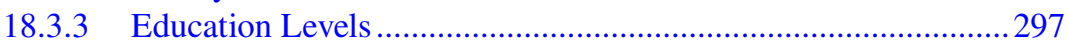

18.3.4 Community Perception of Salinity ................................................297

18.3.5 Sources of Livelihoods............................................................297

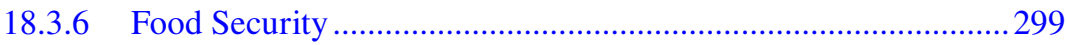

18.3.7 Salinity-Tolerant Livelihoods and Agricultural
Practice in Shyamnagar .................................................................300

18.3.8 Peoples' Interest in Adopting Saline Tolerant

Agricultural Practices .................................................................... 302

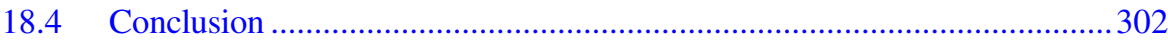

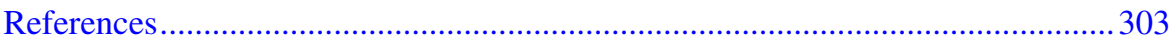

\subsection{INTRODUCTION}

Saline water intrusion is a common problem in the coastal areas of Bangladesh. Climate change-induced hazards including sea level rise, cyclones, storm surges and tidal inundation are contributing to this problem causing salinity ingression into water and land (Baten et al. 2015). The southwestern coastal region of Bangladesh is a food deficit area where net food production and the diversity of food production have declined significantly over recent decades due to the salinity problem. Regular devastating cyclonic storm surges, sea level rise and tidal inundation have 
changed the level of salinity and these have increased the risks associated with normal crop production. The impacts of climate change on coastal regions include inundation from sea level rise, damage from storm surges and loss of water bodies and increased salinity of land from saltwater ingression. Including the coastal region of Bangladesh, worldwide about 600 million people currently inhabit low-elevation coastal zones that will be affected by progressive salinization (Wheeler 2011). One study predicts that the sea level may rise $1 \mathrm{~m}$ or more in the 21st century, which would increase the vulnerability of about 1 billion people by 2050 (Brecht et al. 2012, Dasgupta et al. 2015, Hansen and Sato 2012, Veermer and Rahmstorf 2009, Pfeffer et al. 2008). Normal agricultural land use practices are becoming more restricted due to the increasing degree of salinity and expansion of affected areas (Karim 1990). As a consequence, crop yields, cropping intensity and production levels have decreased more than in any other part of the country (Rahman and Ahsan 2001). SRDI (2010) notes that the affected areas of Bangladesh are still increasing rapidly. In the last four decades, the total salinity-affected area has increased from 0.833 Mha to $1.056 \mathrm{Mha}$. The worst salinity conditions are reported to be in the Khulna, Bagerhat, Satkhira and Patuakhali districts (SRDI 2010). Our research focused on the Shyamnagar Upazila which is in Satkhira district, adjacent to the Bay of Bengal and the mangrove forest of the Sundarbans. Being close to the Bay of Bengal, the area is highly vulnerable to salinity intrusion into agricultural land from cyclones, storm surges and tidal surges, impacts from sea level rise, drainage congestion and flooding (Figure 18.1).

Many coastal districts, including Satkhira, are facing increased levels of salinity in agricultural fields (Islam et al. 2015). Data from the Soil Resource Development Institute (SRDI) shows that in the top soil (upper $15 \mathrm{~cm}$ ) of cultivated areas in Shyamnagar Upazilla, 71\% are affected by high-level salinity (EC in a saturated extract $\left(\mathrm{EC}_{\mathrm{e}}\right)$ above $\left.12 \mathrm{dS} / \mathrm{m}\right)$. About 500 ha of agricultural land become saline in each year. In 2000, the average $\mathrm{EC}_{\mathrm{e}}$ was about $23.9 \mathrm{dS} / \mathrm{m}$, but by 2009 this had increased to about $28.6 \mathrm{dS} / \mathrm{m}$ in Shyamnagar Upazila (SRDI 2010). In 2018, average $\mathrm{EC}_{\mathrm{e}}$ values of $32.0 \mathrm{dS} / \mathrm{m}$ were reported in the Barokupat village of Shyamnagar (Rahaman et al. 2018).

The area of land suited to the cultivation of rice in Syamnagar has also changed with time. According to Kibria (2016), the area cultivated to rice was 21,350 ha in 1996; this had decreased to 14.925 ha by 2008 and had fallen to 5,020 ha by 2013; these declines were all due to salinity intrusion into paddy fields.

It is expected that sea levels along the coast of Bangladesh will rise by $14 \mathrm{~cm}, 32$ $\mathrm{cm}$ and $88 \mathrm{~cm}$ by 2030, 2050 and 2100 respectively (Baten et al. 2015). Sea Level Rise (SLR) will push saline water further inland and affect not only rice production but also other agricultural practices in the future. One study has estimated that Bangladesh may lose 0.2 million tons of crops due to saline intrusion in a moderate climate scenario, but this decline might more than double with a severe climate scenario (Huq and Ayers 2008).

Our study was conducted to explore the salinity-tolerant developed indigenous technologies and planned interventions adopted by farmers. Though several studies had been conducted in terms of climate-resilient farming practices, no integrated study had been conducted to explore the indigenous and planned technologies in the study area. 


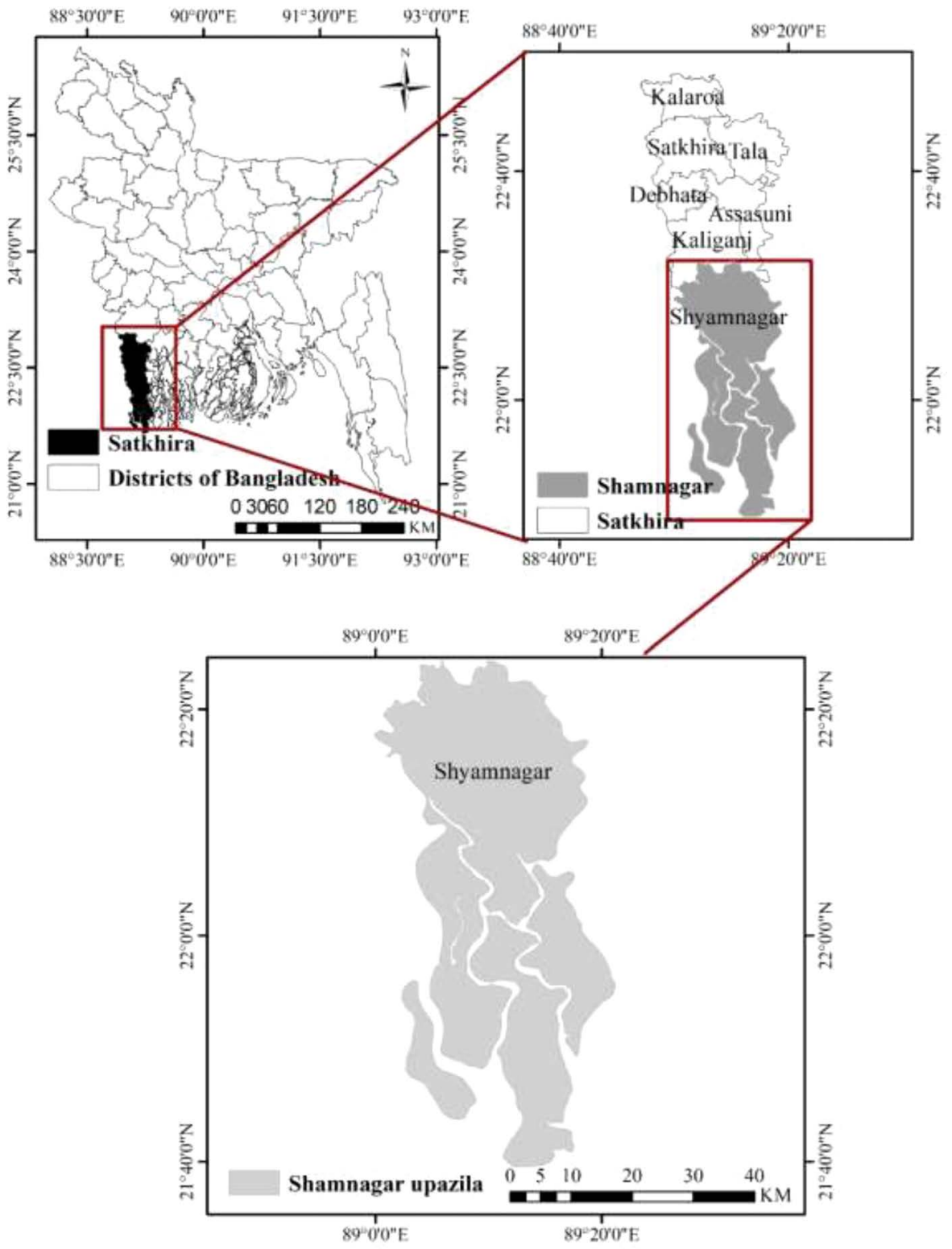

FIGURE 18.1 Map of the Shyamnagar Upazila, showing its location in Satkhira District within southern Bangladesh. 


\subsection{METHODOLOGY}

The study aimed to explore the salinity-tolerant agricultural practices developed and adopted by farmers through the collection of field data and data from other secondary sources. The available scientific literatures related to the impact of salinity on agriculture were reviewed. The study incorporated both qualitative and quantitative information from secondary sources including the Department of Agricultural Extension (DAE), the Department of Fisheries (DoF), the Department of Livestock (DLS), the SRDI and through the reviewing of available literature related to salinity-tolerant agricultural practices in the study area. Primary information was collected through household surveys (HHS), Focus Group Discussions (FGD), Key Informants Interviews (KII), case studies and field observation and consultation with different stakeholders including the DAE, local government institutions and farmers, the Livestock Department, the Fisheries Department and NGOs involved in salinity-tolerant agricultural promotional activities in the study area (Table 18.1).

\subsubsection{Household Survey}

The HSS was conducted among climate-vulnerable people including smallholders, women, fishermen, livestock farmers. In the study, 60 respondents were male and 40 respondents were female. The respondents were selected randomly using multicriteria like land size, household income level and whether they conducted livestock rearing, were fisher folk, or practiced homestead farming.

\subsubsection{Focus Group Discussion}

FGDs were conducted among different farming communities including crop farmers, paddy farmers, fisher folk, livestock farmers and women farmers to explore the salinity-tolerant practices in the study area. In each focus group, 10-12 participants from the respective group were selected based on homogenous farming practice.

\section{TABLE 18.1}

\section{Primary Data Collection Tool and Sample Size for the Target People in Shyamnagar Upazila of Satkhira, Bangladesh}

Data Collection Tool
Households survey
Focus group discussion
Key informant
interviews

Case studies
Target People

Climate-vulnerable people

Sample Size

100

$\begin{array}{ll}\text { Climate-vulnerable people } & 10\end{array}$

Department of Agricultural Extension, local government 8 institutions, Department of Livestock, Department of Fisheries, NGOs

Best practice documentation on salinity-tolerant interventions related to agriculture, livestock, fisheries 


\subsubsection{Key InFormant INTERVIEWS}

Key informant interviews were conducted at Upazila level with DLS, DAE, LGI, DoF and NGOs who are involved with agriculture in the study area.

\subsection{RESULTS AND DISCUSSION}

\subsubsection{Household Types and Respondents}

One hundred respondents (including women) who are involved with farming (crop, fish, livestock, poultry and homestead farming) were interviewed as part of this study. Among these respondents, 69\% were males and $31 \%$ were females. Within households, $63 \%$ were headed by males and rest of the households were headed by females. Regarding religion, $83 \%$ were Muslim, $11 \%$ were Hindu and $6 \%$ were Christian.

\subsubsection{Family Size}

The average household size in the surveyed population was approximately five members. A majority of households (74\%) had medium size families with four-six members while $11 \%$ had small families (one-three members) and another $15 \%$ had comparatively large families comprising seven or more members.

\subsubsection{Education Levels}

Of the households surveyed, $97 \%$ had someone who had obtained some level of education. Among the educated members, $17 \%$ had achieved primary education, $51 \%$ reached secondary education and $29 \%$ had obtained post-secondary education.

\subsubsection{Community Perception of Salinity}

Members of the community were invited to reflect on whether their land had no salinity or low, moderate or high salinity in 1998, 2008 and 2018. Most of the respondents of the study claimed that salinity intrusion had increased over the last decade (Figure 18.2). In 1998, 13\% of respondents observed no salinity in the study area but over course of time salinity had increased, and in 2008 it stood at $9 \%$ and in 2018 it stood at only $5 \%$. In 2018, 33\% respondents claimed that they were affected by high salinity but $83 \%$ of respondents argued that rice production was restricted in the paddy field due to salinity.

\subsubsection{SOURCES OF Livelihoods}

The sources of livelihoods of the respondents are summarized in Figure 18.3. Due to the loss in agricultural production, most of the respondents depended on fishing and extracting resources from the forest for their livelihoods; these included the collection of honey, firewood, fish, goalpata and crabs. Some of the respondents depended on small farming and fish farming as well as shrimp farming on their land. About 


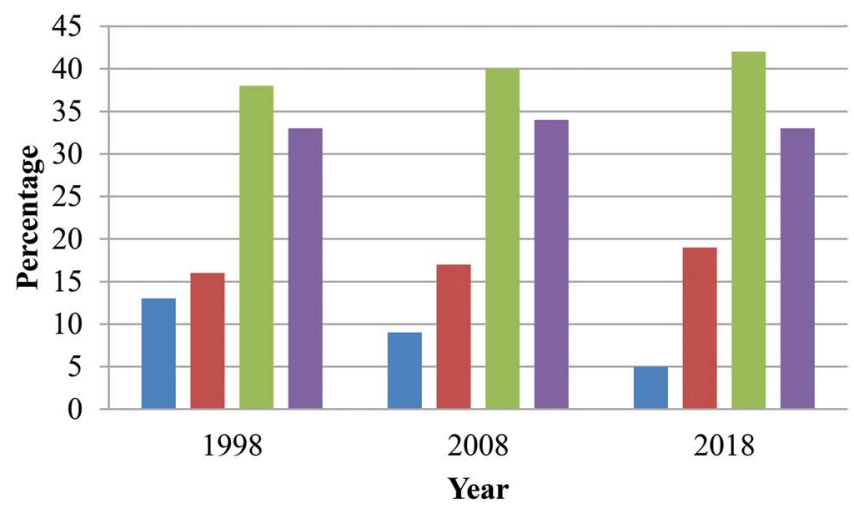

no Salinity $\quad$ Low $\backsim$ Medium $\quad$ High

FIGURE 18.2 Perception of changes in salinity trends in the study area. Salinity classes were: no salinity $\left(\mathrm{EC}_{\mathrm{e}}\right.$ values below $\left.2 \mathrm{dS} / \mathrm{m}\right)$, low salinity-affected soil $\left(\mathrm{EC}_{\mathrm{e}}\right.$ values $\left.2-8 \mathrm{dS} / \mathrm{m}\right)$, medium salinity-affected soil $\left(\mathrm{EC}_{\mathrm{e}}\right.$ values $\left.8.1-16 \mathrm{dS} / \mathrm{m}\right)$ and high salinity-affected soil $\left(\mathrm{EC}_{\mathrm{e}}\right.$ values above $16 \mathrm{dS} / \mathrm{m})$.

$2 \%$ of respondents earned wages as day laborers. Small trading, rickshaw pulling, day labor, small cottage industries and boating are wage earning sources of income of the respondents. Most (65\%) households depended on natural resources for their livelihoods. A small proportion of households (5.5\%) produced small livestock and poultry (like goats, duck and chicken) and livestock products. $84 \%$ of them produced fuel wood for household consumption. They also caught fish (57\%) as well as collecting honey (30.1\% of households).

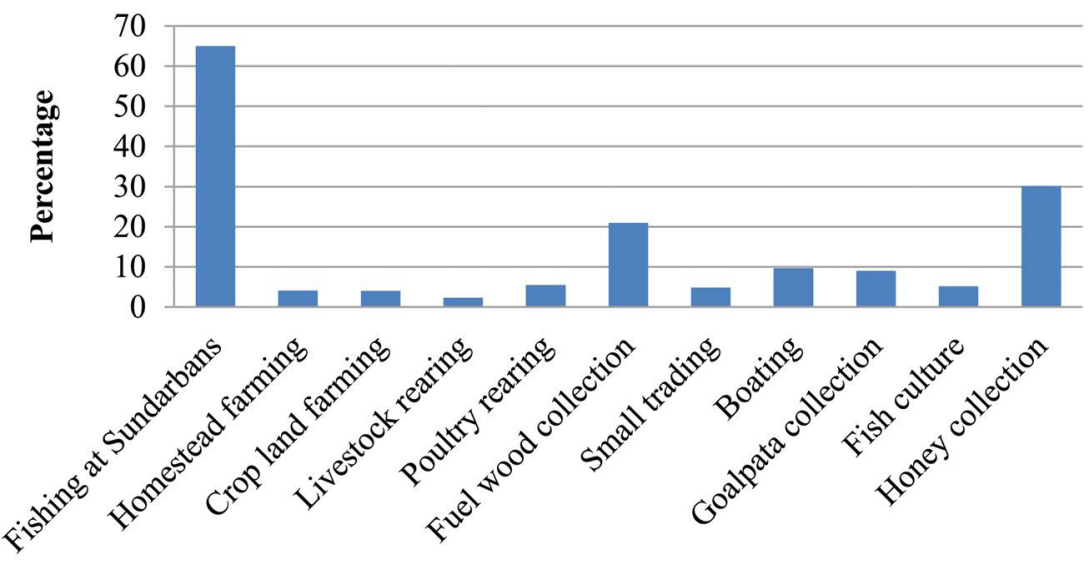

Sources of Income

FIGURE 18.3 Source of livelihoods of the respondents in 2018. The number of households surveyed was 100 , but many households had more than one source of income so the total of all sources exceeds 100 . 


\subsubsection{Food SECURITY}

The monthly sources of food for the household were investigated and classified as to whether they came from their own farm, from off-farm sources or from the market for each month (on an average year). The survey found that only $2.1 \%$ of households consumed their own farm products for about three months a year, an average of $16 \%$ of households consumed food from off-farm sources throughout the year, and the rest of households depended on the market for their food products. Overall, only $31 \%$ of households were able to achieve food security. Respondents were also asked during which months of the year they struggled to have enough food to feed their household, from any source. Figures 18.4 and 18.5 indicate the sources of food and the months when the majority of households suffered from food insecurity in the study area.

Figure 18.4 shows the percentage of households who consume food from their own sources in a year. It is clear that the majority of households in Shyamnagar take food from market sources for six-eight months and they have to fully depend on the market during August-November. During this time, many of them also depend on off-farm sources such as relatives, friends and public food. The survey data also show that many households suffer from food shortages during July-November in this locality. Figure 18.5 shows a trend of food shortage (unable to meet the daily

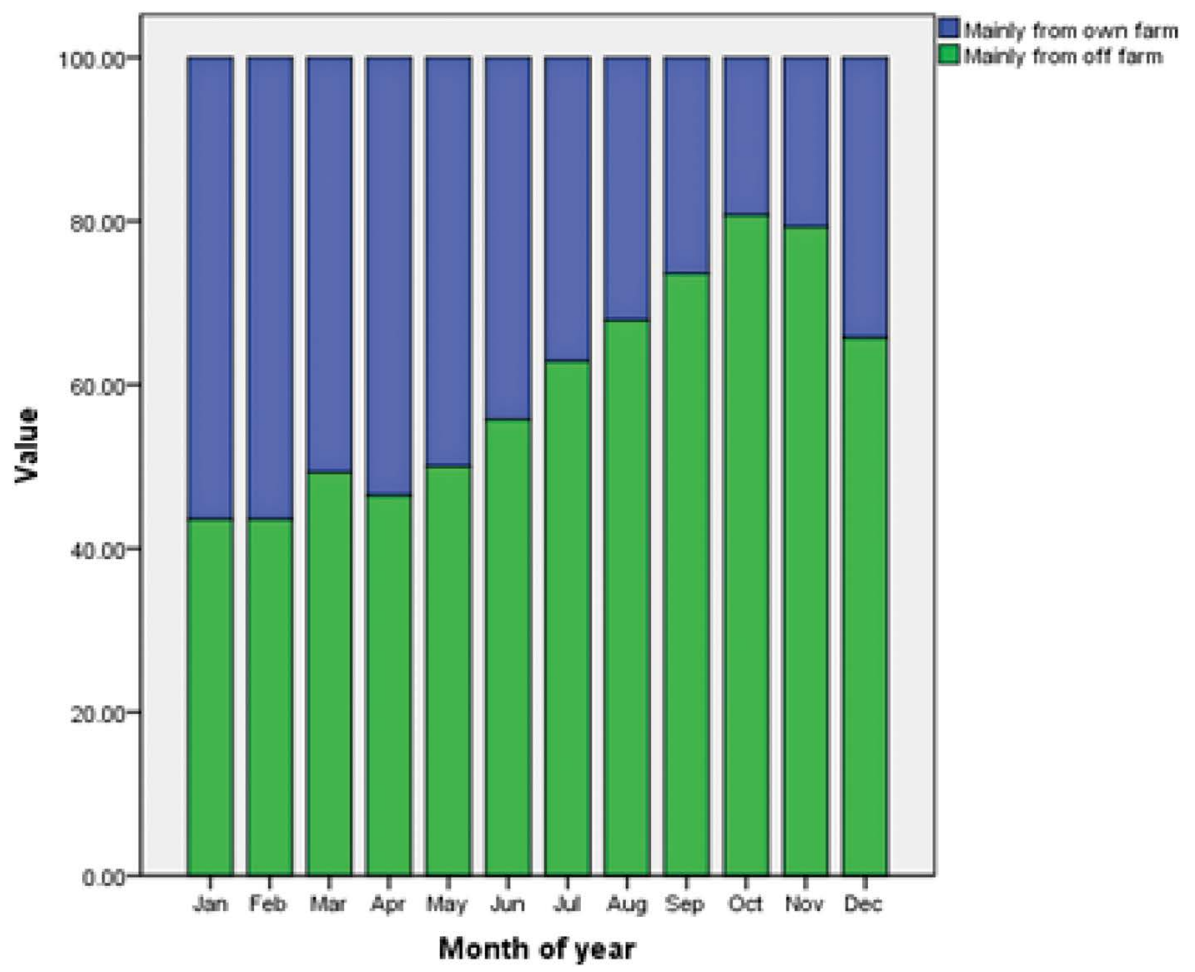

FIGURE 18.4 Effect of month of year on the main source of food for the household. 


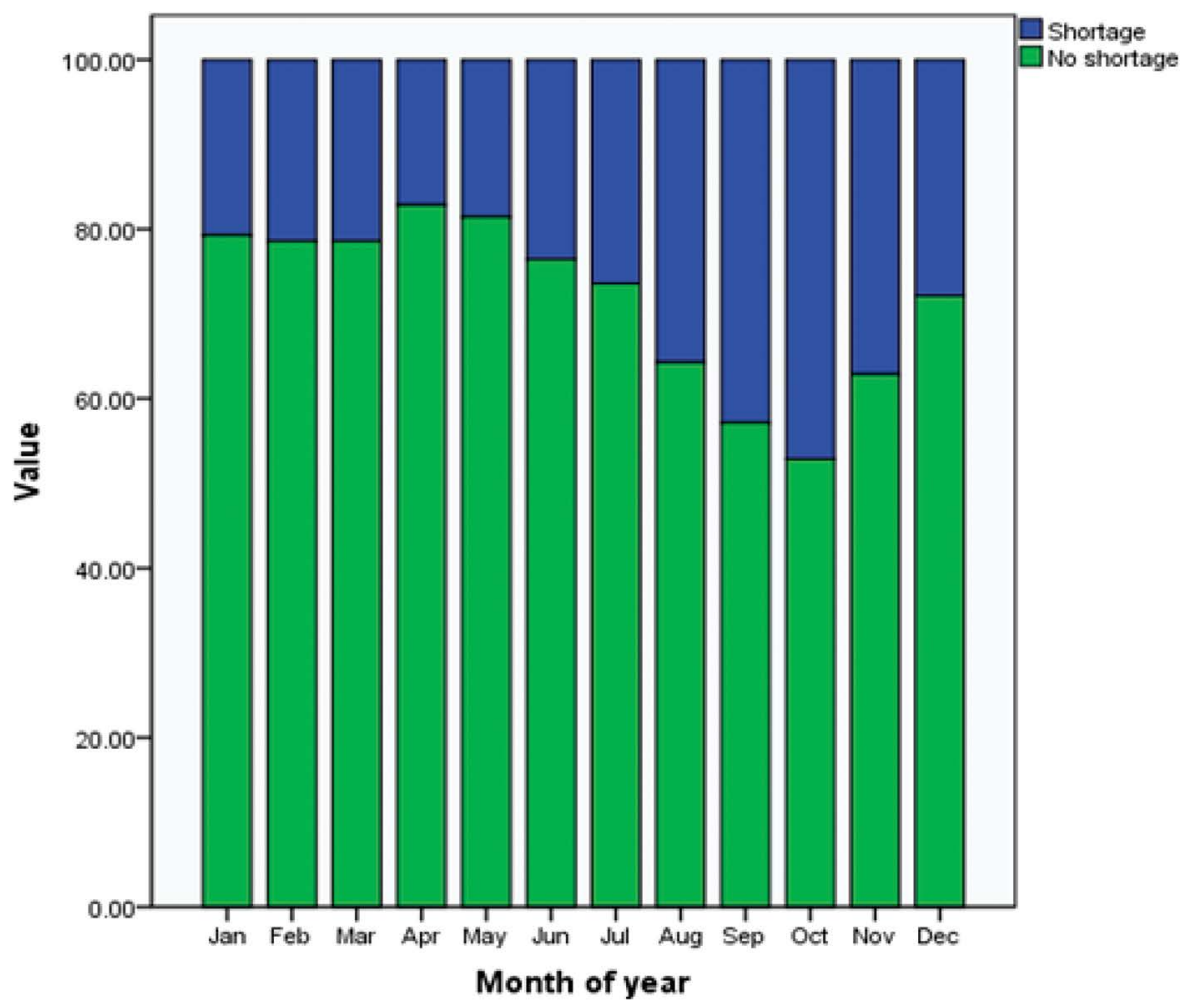

FIGURE 18.5 Food shortage months.

needs) in the study villages in Satkhira. It is to be noted that all households have some food shortage at all months of the year, but the shortages are most severe in August-December, and food shortage was greatest in October.

\subsubsection{Salinity-Tolerant Livelihoods and Agricultural Practice in Shyamnagar}

Many agricultural adaptation options are being practiced in Bangladesh to adapt to climate induced agricultural disasters like salinity, flood, waterlogging, drought, etc. Some of these innovations are devised by local communities through their indigenous knowledge, and some are planned interventions promoted by different government and non-government organizations (Rahaman et al. 2018). According to Nelson et al. (2007) and Alam et al. (2013), floating bed farming in the south-central and southern areas, plant bed raising and dyke cropping on the shrimp gher (water bodies which are artificially generated through raising dykes around the lowland) is an old but effective practice used nowadays.

The following are the key resilient agricultural and livelihood practices which were found in the study area to cope with salinity intrusion and ensure resilient 


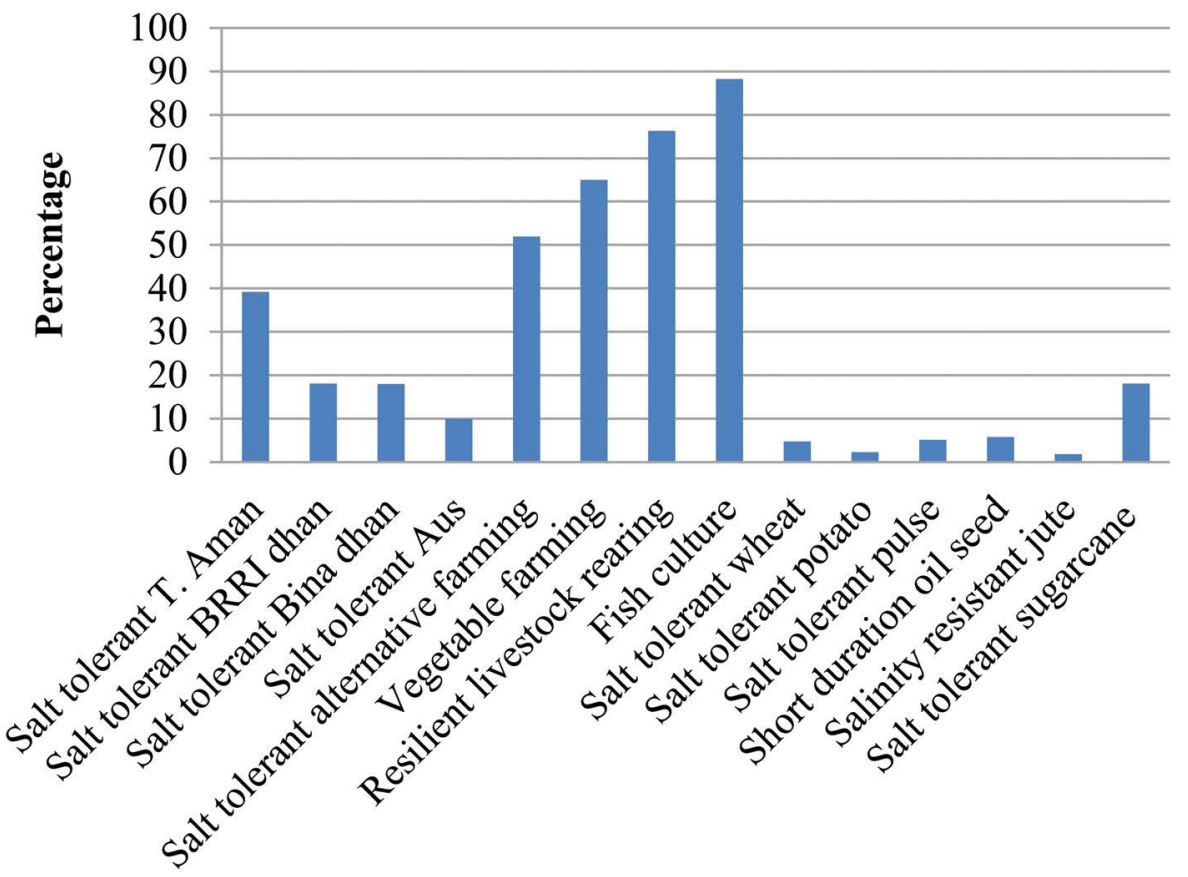

Salinity Tolerant Practices

FIGURE 18.6 Salinity-tolerant practices used at Shyamnagar Upazila. (Source: Rahaman et al. 2018 and Field Study, 2019.)

livelihoods. The research indicates (Figure 18.6) that $31.3 \%$ of the farmers of the Shyamnagar Upazila are presently interested to adopt alternative land use practices like shrimp farming instead of crop production. Though the use of land for crop farming is decreasing gradually, there are some alternative options for agriculture emerging. The major salinity-tolerant practices of the study area which were identified by the different respondents (including farmers, agricultural professionals, government and non-government organizations who are involved with resilient livelihoods) include interventions like: (a) the introduction of salinity-tolerant rice varieties (such as T. Aman: BR-22 and BR-23; Bina shail; BRRI dhan 33, 40, 41, 46, 49, 53, 54, 56, 57, 62 and 65; Bina dhan 7, 8, 10 and 16), (b) cage fishing, (c) mele (reed) cultivation, (d) floating dhap cultivation (the practice of growing vegetable seedlings on water beds), (e) shifting the planting time of crops, (f) growing short duration rice varieties, (g) integrated farming, (h) crab farming, (i) semi-scavenger housing for goat, duck and hen rearing, (j) net fishing, (k) dyke farming, (l) the growth of salt-tolerant wheat (like Bijoy, BARI Gom-25, BAU-1059), (m) the growth of salt-tolerant potato (e.g. BARI Alo-22, CIP Clone 88, 163), (n) the growth of salt-tolerant sweet potato (e.g. BARI Mishti Alo-8,9), (o) the growth of salt-tolerant pulses (e.g. BARI Mug-2, 3, 4, 5, 6, BM-01, BM-08; BARI Falon-1, BARI Sola-9), (p) the growth of short duration and salt-tolerant oilseeds (e.g. BARI Sharisha-14,15; BARI Chinabadam-9, BINA 


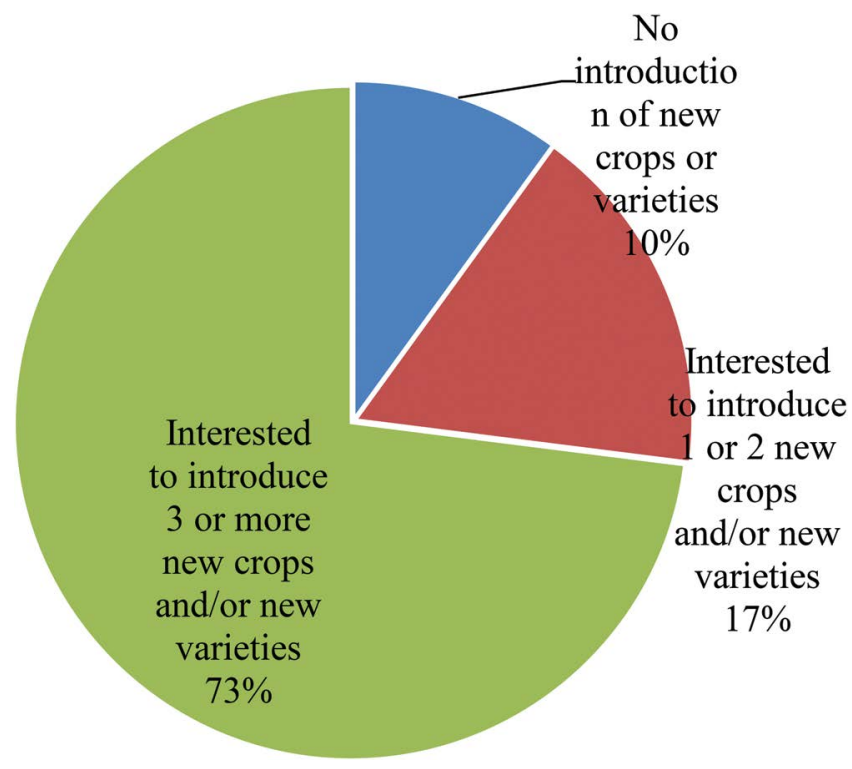

FIGURE 18.7 Development and adoption of saline tolerant crops/varieties.

China badam-1, BINA China badam-2, BARI Soyabean-6 BARI Til-2, 3, 4), (q) the growth of salt-resistant jute varieties (e.g. Bangladesh Jute Research Institute (BJRI): (i) HC-2, (ii) HC 95, (iii) CVL 1); and (iv) the growth of salt-tolerant sugarcane varieties from the Bangladesh Sugarcane Research Institute (BSRI) (eg. ISWARDI-40). Figure 18.6 shows that $39.2 \%$ of farmers use salt-tolerant T. Aman rice varieties BR-22, BR 23, BR 22 and Bina shail and $18.1 \%$ of farmers use salt-tolerant BRRI dhan (Rahaman et al. 2018 \& Field Study 2019).

\subsubsection{Peoples' Interest in Adopting Saline Tolerant Agricultural Practices}

Due to food insecurity, most of the respondents have developed and adopted saline tolerant agricultural practices in the study area. $74 \%$ of respondents were interested to incorporate three or more new crops or varieties into their farming systems if they could get seed and capacity building support, while $17 \%$ were interested to introduce one or two new crops or varieties and $9 \%$ of households had no interest in any new crops or varieties because they do not own their own land for cultivation (Figure 18.7).

\subsection{CONCLUSION}

Our study has provided a unique portrait of a community at major risk of salinity from climate change. Most of the people of Shyamnagar are severely affected by salinity intrusion onto their land. They are trying to live with salinity in different ways. 
Our study found that $39 \%$ farmers have developed saline tolerant technologies for home gardening, livestock rearing, fish farming, crab farming by their own knowledge, and $61 \%$ of the farmers have adopted saline tolerant verities for crop farming in their crop provided by government and non-government organizations. The government is mainly providing different varieties of rice, wheat and vegetables, but each year, people have a decreased capacity to adapt to the progressive spread of salinity. It is therefore time to think about long-term adaptation technologies in the salinity-affected areas and areas that could potentially be affected. Along with the innovation of agricultural technology and saline tolerant varieties, agricultural land needs to be protected from salinity intrusion and context-specific practices, including saline tolerant rice cultivation (seeds and methods), must be researched and implemented. In this work, it will be important to concentrate on the problems to coastal communities of saline intrusion caused by extreme events (e.g. cyclones Sidr and Aila).

\section{REFERENCES}

Alam, M., R. Ahammad, P. Nandy, and S. Rahman. 2013. "Coastal livelihood adaptation in changing climate: Bangladesh experience of NAPA priority project implementation." In Climate change adaptation actions in Bangladesh, 253-276. Springer, Switzerland.

Baten, M. A., L. Seal, and K. S. Lisa. 2015. "Salinity intrusion in interior coast of Bangladesh: challenges to agriculture in south-central coastal zone." American Journal of Climate Change no. 4 (03):248.

Brecht, H., S. Dasgupta, B. Laplante, S. Murray, and D. Wheeler. 2012. "Sea-level rise and storm surges: High stakes for a small number of developing countries." The Journal of Environment \& Development no. 21 (1):120-138.

Dasgupta, S., M. M. Hossain, M. Huq, and D. Wheeler. 2015. "Climate change and soil salinity: The case of coastal Bangladesh.” Ambio no. 44 (8):815-826.

Hansen, J. E., and M. Sato. 2012. "Paleoclimate implications for human-made climate change." In Climate change, 21-47. Springer, Switzerland.

Huq, S., and J. Ayers. 2008. Climate change impacts and responses in Bangladesh. Policy Department Economy and Science, European Parliament, Brussels, Belgium.

Islam, M. A., P. K. Shitangsu, and M. Z. Hassan. 2015. "Agricultural vulnerability in Bangladesh to climate change induced sea level rise and options for adaptation: a study of a coastal Upazila." Journal of Agriculture and Environment for International Development (JAEID) no. 109 (1):19-39.

Karim, Z. 1990. Salinity problems and crop intensification in the coastal regions of Bangladesh. Soil Publication No. 33. Dhaka, Bangladesh.

Kibria, G. 2016. "Storm surge propagation and crop damage assessment in a coastal polder of Bangladesh. Post graduate Dissertation, Bangladesh University of Engineering Technology (BUET), Dhaka, Banaagladesh"

Nelson, D. R., W. N. Adger, and K. Brown. 2007. "Adaptation to environmental change: contributions of a resilience framework." Annual Review of Environment and Resources.32:395-419.

Pfeffer, W. T., J. T. Harper, and S. O’Neel. 2008. "Kinematic constraints on glacier contributions to 21st-century sea-level rise." Science no. 321 (5894):1340-1343.

Rahaman, M. A., M. Rahman, and S. Hossain. 2018. "Climate-resilient agricultural practices in different agro-ecological zones of Bangladesh." In Handbook of climate change resilience, edited by Walter Leal Filho. Springer Nature, Switzerland. 
Rahman, M., and M. Ahsan. 2001. "Salinity constraints and agricultural productivity in coastal saline area of Bangladesh." Soil Resources in Bangladesh: Assessment and Utilization no. 1:1-14.

SRDI. 2010. Saline Soils of Bangladesh. edited by SRMAF Project Soil Resource Development Institute. Dhaka: Ministry of Agriculture, Mrittika Bhaban, Krishikhamar Sarak Farmgate, Dhaka-1215.

Veermer, M., and S. Rahmstorf. 2009. "Global sea-level linked to global temperatura." Proceeding National Academy of Science United States no. 106 (51):21521-21532.

Wheeler, D. 2011. "Quantifying vulnerability to climate change: implications for adaptation assistance." Center for Global Development Working Paper (240). 